\title{
Public Health Law: A Renaissance
}

Lawrence O. Gostin

Georgetown University Law Center, gostin@law.georgetown.edu

This paper can be downloaded free of charge from:

https://scholarship.law.georgetown.edu/facpub/1818

30 J.L. Med. \& Ethics 136-140 (2002)

This open-access article is brought to you by the Georgetown Law Library. Posted with permission of the author. Follow this and additional works at: https://scholarship.law.georgetown.edu/facpub

Part of the Health Law and Policy Commons 


\section{Public Health Law: A Renaissance}

\section{Lawrence O. Gostin}

$\mathrm{T}$

his symposium issue of the Journal of Law, Medicine of Ethics is about public health law, not health-care law. There is a difference. Most scholarly writing has examined the rich and textured field of health-care law or law and medicine. This field revolves around several broad themes related to the health-care system: delivery, financing, and research and innovation.

In studying health-care delivery, scholars have examined everything from the physician/patient relationship (e.g., consent and privacy) to systems of care (e.g., hospitals and managed care organizations). In studying financing, scholars have examined theories of competition and justice to ensure cost-efficient access to care. And in studying research and innovation, scholars have studied everything from human subject protection to intellectual property.

Public health, by contrast, seeks to assure the conditions for people to be healthy. Public health can be distinguished from health care in several critical respects. Public health focuses on: (1) the health and safety of populations rather than the health of individual patients; (2) prevention of injury and disease rather than treatment and care; (3) relationships between the government and the community rather than the physician and patient; and (4) populationbased services grounded on the scientific methodologies of public health (e.g., biostatistics and epidemiology) rather than personal medical services. These critical features - populations, prevention, government and communities, and epidemiological services - are the hallmarks of public health.

The importance of public health came into sharp focus with the events of September 11 and its aftermath. The public has come to see the critical value of health, safety, and security. Many threats to health can be prevented or amelio-

Journal of Law, Medicine do Ethics, 30 (2002): 136-140. (C) 2002 by the American Society of Law, Medicine \& Ethics. rated by careful surveillance and targeted interventions e.g., bioterrorism, naturally occurring infectious diseases, or chronic diseases caused by genetics, behavior, or the environment. But for public health to work effectively, it needs strengthening, including a well-trained and competent workforce, laboratory capacity, and stable sources of noncategorical funding.

The legal basis for public health is nearly as important as its workforce and funding. Public health cannot function well unless it has strong legal foundations. The law relating to public health can be divided into two overlapping ideas: (1) public health law, which is the body of statutes and regulations that provides the foundations for public health agencies - e.g., mission, duties, and powers; and (2) law and the public's health, which are those wide-ranging statutes and regulations intended to improve morbidity and mortality rates across the population - e.g., safety rules for motor vehicles, occupational health, and drinking water.

\section{Public Health Law: The Mission, Duties, and Powers of Public Health Agencies}

Each state has a legal framework that establishes the mission, functions, powers, and structure of public health agencies. These laws are highly important because they provide the foundations for public health practice within the state and its localities. My colleagues ( $\mathrm{Scott}$ Burris and Zita Lazzarini) and I have argued that multiple problems of antiquity, inconsistency, redundancy, and ambiguity render these laws ineffective, or even counterproductive, in advancing the population's health. In particular, health codes frequently are outdated, built up in layers over different periods of time, and highly fragmented among the fifty states and territories.

Problem of Antiquity. The most striking characteristic of state public health law and the one that underlies many of 
its defects is its overall antiquity. Certainly, some statutes are relatively recent in origin. However, a great deal of public health law was framed in the late nineteenth and early to mid-twentieth century and contains elements that are 40 to 100 years old. Old public health statutes are often outmoded in ways that directly reduce their effectiveness and conformity with modern standards. These laws often do not reflect contemporary scientific understandings of injury and disease (e.g., surveillance, prevention, and response) or legal norms for protection of individual rights.

Problem of Multiple Layers of Law. Related to the problem of antiquity is the problem of multiple layers of law. The law in most states consists of successive layers of statutes and amendments, built up in some cases over 100 years or more in response to existing or perceived health threats. This is particularly troublesome in the area of infectious diseases, which forms a substantial part of state health codes. Because communicable disease laws have been passed piecemeal in response to specific epidemics, they tell the story of the history of disease control in the United States (e.g., smallpox, cholera, tuberculosis, sexually transmitted diseases, polio, and AIDS). The disparate legal structure of state public health laws can significantly undermine their effectiveness. Laws enacted piecemeal over time are inconsistent, redundant, and ambiguous. Even the most astute lawyers in public health agencies or attorney general offices have difficulty understanding these arcane laws and applying them to contemporary health threats.

Problem of Inconsistency Among the States and Territories. Public health laws remain fragmented not only within states but among them. Health codes within the fifty states and territories have evolved independently, leading to profound variation in the structure, substance, and procedures for detecting, controlling, and preventing injury and disease. In fact, statutes and regulations among American jurisdictions vary so significantly in definitions, methods, age, and scope that they defy orderly categorization. There is good reason for greater uniformity among the states in matters of public health. Health threats are rarely confined to single jurisdictions, but pose risks within whole regions or the nation itself (e.g., air or water pollution, disposal of toxic waste, and bioterrorism).

Public health law, therefore, should be reformed so that it conforms with modern scientific and legal standards, is more consistent within and among states, and is more uniform in its approach to different health threats. A single set of standards and procedures would add needed clarity and coherence to legal regulation, and would reduce the opportunity for politically motivated disputes about how to classify newly emergent health threats. The reform effort is currently underway through the Robert Wood Johnson Foundation's Turning Point Program (www.turningpointprogram.org). The program seeks to transform the public health system to make it more effective, community-based, and collaborative. No- tably, Turning Point supports the Public Health Statute Modernization National Collaborative, a consortium of states and national public health organizations (http://health.hss.state. ak.us/dph/deu/turningpoint/the_collaborative.htm). The collaborative is conducting a comprehensive analysis of the structure and appropriateness of state public health statutes and developing a model state public health law.

When government and the public experienced the fear of bioterrorism caused by the intentional dispersal of anthrax through the postal system, we recognized our vulnerability. In response, the Centers for Disease Control and Prevention (CDC) asked the Center for Law and the Public's Health at Georgetown and Johns Hopkins Universities to prepare a Model State Emergency Health Powers Act. The Model Act, written in collaboration with governors, legislators, attorneys general, and health officials, and prepared by the Center for Law and Public's Health, seeks to modernize public health laws to ensure preparedness for a bioterrorist attack or a novel naturally occurring infectious disease. The Model Act is reproduced as an appendix to this symposium and can also be accessed at the center's website (www.publichealthlaw.net).

\section{Law and the Public's Health: Models of Public Health Intervention}

The law relating to public health provides not only foundations for agency action, but also a set of tools to improve the public's health. There are at least five models for legal intervention designed to prevent injury and disease and promote the public's health. While legal interventions can be effective, they often raise social, ethical, or constitutional concerns that warrant careful study.

Model one is the power to tax and spend. This power, found in federal and state constitutions, provides government with an important regulatory technique. The power to spend enables government to set conditions for the receipt of public resources (e.g., federal highway funds granted on condition that states set the minimum drinking age at twenty-one). The power to tax similarly provides disincentives to engage in risk behavior (e.g., cigarette taxes) and incentives to provide beneficial services (e.g., tax relief for employer health benefits). The spending and taxing power, however, are not entirely benign. Taxing and spending can be seen as coercive because the government wields significant economic power. Additionally, taxing and spending can be inequitable if rich people benefit (e.g., the oil depletion allowance) or the poor are disadvantaged (e.g., cigarette taxes, which are highly regressive).

Model two is the power to alter the informational environment. Government can add its voice to the marketplace of ideas through health promotion activities such as health communication campaigns; provide relevant consumer information through labeling requirements; and limit harmful 
or misleading information through regulation of commercial advertising of unsafe products (e.g., cigarettes and alcoholic beverages). But even these interventions can be controversial. Not everyone believes that public funds should be expended, or the veneer of government legitimacy used, to prescribe particular social orthodoxies - e.g., unsafe sex, abortion, smoking, high fat diet, or sedentary lifestyle. Labeling requirements seem unobjectionable, but businesses strongly protest compelled disclosure of certain kinds of information - e.g., genetically modified foods. Similarly, businesses oppose regulation of advertising, claiming that it is a violation of their right to free speech.

Model three is direct regulation of individuals (e.g., seat belt and motorcycle helmet laws), professionals (e.g., licenses), or businesses (e.g., inspections and occupational safety standards). Public health authorities regulate pervasively to reduce risks to the population. Most people recognize the value of public health regulation, but coercive government action inevitably interferes with personal or economic liberty. Public debate frequently centers on paternalistic regulation such as water fluoridation or burdensome and costly regulation that interferes with free enterprise.

Model four is indirect regulation through the tort system. Tort litigation can provide strong incentives for businesses to engage in less risky activities. Litigation has been used as a tool of public health to influence manufacturers of automobiles, cigarettes, and firearms. Litigation has resulted in safer automobiles; reduced advertising and promotion of cigarettes to young people; and encouraged at least one manufacturer (Smith \& Wesson) to develop safer firearms. At the same time, litigation may be anti-democratic and unfair. Critics claim that the policymaking branch of government, not the judiciary, should make judgments about unsafe products. They also point out that the financial benefits of litigation frequently go to a few plaintiffs and their attorneys rather than to the entire population that has been harmed.

The final model, model five, is deregulation. Sometimes laws are harmful to public health and stand as an obstacle to effective action. For example, criminal laws proscribe the possession and distribution of sterile syringes and needles. These laws, therefore, make it more difficult for public health authorities to engage in HIV-prevention activities. Deregulation can also be controversial since it often involves a direct conflict with a set of laws representing another set of values. For example, the criminal law represents society's disapproval of drug use and its intention to punish those who make it easier to inject unlawful drugs. Deregulation becomes a symbol of weakness in the fight against drugs.

The government, then, has many legal "levers" designed to prevent injury and disease and promote the public's health. Legal interventions can be highly effective and need to be part of the public health officer's arsenal. At the same time, legal interventions can be controversial, raising important ethical, social, constitutional, and political issues. These conflicts are complex, important, and fascinating for students of public health law. This groundbreaking volume of the Journal of Law, Medicine \& Ethics examines these kinds of legal interventions and the inevitable trade-offs between collective and individual interests.

\section{A Symposium on Public Health Law}

This is one of the first, if not the first, symposium devoted entirely to public health law in a major journal. Its importance is underscored by the fact that the able leaders of the CDC have written the issue's foreword. The CDC has formed a public health law program for the first time in its history (www.phppo.cdc.gov/phlawnet). The public health law program established a CDC Collaborating Center - the Center for Law and the Public's Health at Georgetown and Johns Hopkins Universities (www.publichealthlaw.net). The CDC also gives grants to researchers to investigate the links between law and population health and is holding a national conference on public health law this June in Atlanta ("The Public's Health and the Law in the 21st Century").

This symposium issue defines public health law, examines it parameters, and discusses salient areas of concern. The symposium is divided into four parts: (1) the legal, ethical, and social aspects of public health; (2) fields of law relevant to public health; (3) salient issues in public health law; and (4) the future of public health law. The appendix contains the Model State Emergency Health Powers Act prepared to combat bioterrorism and novel naturally occurring infectious diseases.

\section{Part I: Public health law, society, and ethics}

The articles by Professor Mark Rothstein of the University of Louisville and Professor David Fidler of Indiana University explore the meanings of public health law. The insights of these two leading health law scholars provide a sophisticated account of public health law in the United States (Rothstein) and internationally (Fidler). These scholars richly supplement, and in some respects dissent from, the theory and definition I offer in my recent book, Public Health Law: Power, Duty, Restraint (Milbank Memorial Fund and University of California Press, 2000). For a discussion of the ideas and themes of that book, see the thoughtful review by Bernard Dickens of the University of Toronto in this volume.

The law relating to public health should be based on ethical values. Unfortunately, until recently, ethicists have not focused carefully on the population-basis of public health. James Childress and his colleagues at the University of Virginia, University of Minnesota, University of Washington, and Georgetown and Johns Hopkins universities offer an ethical basis for thinking about public health. In particular, 
Childress maps this new terrain of public health ethics, defining public health, identifying several general moral considerations that support and constrain its pursuit, and offering a framework for resolving conflicts among these considerations, with particular attention to screening programs. The field of public health ethics is presently expanding, with important ongoing projects at the Hastings Center (led by Dan Callahan and Bruce Jennings) and the Association of Schools of Public Health.

Also in this section, Professor Scott Burris of Temple University has written insightfully on the subject of the law's role in changing behavior and creating stigmatizing conditions for vulnerable persons. In his article, Burris continues his exploration of law and society, focusing particularly on the issue of stigma in the HIV/AIDS epidemic.

Finally, it is important to emphasize that health care is an important determinant of what makes a population healthy. As discussed above, public health assures the conditions in which people can be healthy. One of those conditions, of course, is access to health care, which today is predominately determined by the practice norms of managed care. Professors Sara Rosenbaum and Brian Kamoie of the George Washington University thoughtfully discuss the relationship between public health and managed care, and what this relationship means for the core functions of public health in the future. What can government do to make sure that economic, social, and cultural barriers to health care are dismantled? What can government do to make sure that health-care providers provide services that help prevent injury and disease from a population-based perspective? These are the questions that Rosembaum has pursued throughout her professional career.

\section{Part II: Fields of law}

Public health law richly incorporates all the major fields of law - e.g., constitutional, administrative, tort, and criminal. The symposium discusses each of these fields. Professor Wendy Parmet of Northeastern University examines public health through the lens of the U.S. Constitution. The Supreme Court has steadily moved to a "states rights" position and Parmet analyzes the implications of this for public health in America, particularly after September 11. Next, Professor Eleanor Kinney of Indiana University examines public health through the lens of administrative law. In the modern administrative state, agencies make and interpret rules and enforce legislative policies. Administrative law is essential for understanding public health.

Professor Peter Jacobson of the University of Michigan and Soheil Soliman then examine public health through the lens of tort law. Increasingly, public health advocates are turning to the courts to achieve health objectives. Jacobson and Soliman analyze the history and practice of tort law in relation to the public's health.
Finally, Professor Zita Lazzarini of the University of Connecticut and her colleagues Scott Burris and Sarah Bray use $\mathrm{HIV}$ as a lens to evaluate the merits of criminal penalties for intentionally exposing others to, or transmitting, infectious disease. Sometimes public health law can be punitive and the AIDS epidemic demonstrates the real possibility of a coercive approach to disease control.

\section{Part III: Salient issues in public health law}

Having examined the theory and parameters of public health law, the symposium goes on to assess some of its most important and controversial areas. Professor James G. Hodge, Jr., of Georgetown University begins with an exploration of bioterrorism. Hodge presents the work of the Center for Law and the Public's Health in drafting the Model State Emergency Health Powers Act. The Model Act is currently being considered by the states. The Model Act was written because of the large gaps in powers under current laws and regulations. Heather Horton and her colleagues at the CDC illustrate the need for law reform from their original research conducted before September 11. The results show that most states did not even require reporting of the major agents of bioterrorism.

Bioterrorism is a relatively recent public health concern. The next two articles discuss long-term public health problems involving major causes of disability and death: injury and tobacco. Professor Richard Bonnie of the University of Virginia and Professor Bernard Guyer of Johns Hopkins University discuss how the mission of public health has come to encompass the prevention and amelioration of unintentional and intentional injury. As members of the Institute of Medicine study on this subject, Bonnie (who was also its chair) and Guyer bring to bear great experience in thinking about this public health problem.

Next, Professor Richard Daynard of Northeastern University discusses the area of tobacco regulation and litigation. Unlike the firearms litigation, the tobacco lawsuits sometimes have had stunning successes and, often, Daynard has been a pivotal figure in this litigation. However, the Supreme Court has been cool to the idea of extensive regulation. In 2000, the Court held that the federal Food and Drug Administration lacked the power to regulate tobacco. In 2001, the Court held that Massachusetts regulations over tobacco advertising were either preempted or a violation of the First Amendment.

The symposium next turns to one of the most exciting emerging fields in public health - genetics. The CDC has a division focused solely on this issue (the Office of Genomics \& Disease Prevention). Professor Ellen Wright Clayton of Vanderbilt University analyzes this field and shows the population-based perspective of the new genetics. Clayton has been a leading figure in the medical and legal aspects of genetics. 
Part IV: The future of public health law

There is an irony to the field of public health law. On the one hand, it is perhaps the oldest area of study in the field of health. On the other hand, it has recently been neglected and left in the shadows of health-care law. Public health law is now emerging as a major field of study. As Richard Goodman at the CDC and his colleagues, and Wendy Parmet and Professor Anthony Robbins of Tufts University, argue in their short papers, it is now time to teach courses and engage in sustained study of this subject in schools of public health, law, medicine, nursing, and health administration. Nothing is more important than the health, safety, and security of the people, and it is time that research, scholarship, and teaching reflected this priority. 